\author{
Marquette University \\ e-Publications@Marquette
}

$11-2009$

\title{
Analysis and Diagnostics of Adjacent and Nonadjacent Broken- Rotor-Bar Faults in Squirrel-Cage Induction Machines
}

Gennadi Y. Sizov

Marquette University

Ahmed Mohamed Sayed Ahmed

Marquette University

Chia-Chou Yeh

Marquette University

Nabeel Demerdash

Marquette University, nabeel.demerdash@marquette.edu

Follow this and additional works at: https://epublications.marquette.edu/electric_fac

Part of the Computer Engineering Commons, and the Electrical and Computer Engineering Commons

\section{Recommended Citation}

Sizov, Gennadi Y.; Ahmed, Ahmed Mohamed Sayed; Yeh, Chia-Chou; and Demerdash, Nabeel, "Analysis and Diagnostics of Adjacent and Nonadjacent Broken-Rotor-Bar Faults in Squirrel-Cage Induction Machines" (2009). Electrical and Computer Engineering Faculty Research and Publications. 199.

https://epublications.marquette.edu/electric_fac/199 
Marquette University

e-Publications@Marquette

\section{Department of Electrical and Computer Engineering Faculty Research and Publications/College of Engineering}

This paper is NOT THE PUBLISHED VERSION.

Access the published version at the link in the citation below.

IEEE Transactions on Industrial Electronics, Vol. 56, No. 11 (November 2009): 4627-4641. DOI. This article is (C) Institute of Electrical and Electronic Engineers (IEEE) and permission has been granted for this version to appear in e-Publications@Marquette. Institute of Electrical and Electronic Engineers (IEEE) does not grant permission for this article to be further copied/distributed or hosted elsewhere without the express permission from Institute of Electrical and Electronic Engineers (IEEE).

\section{Analysis and Diagnostics of Adjacent and Nonadjacent Broken-Rotor-Bar Faults in Squirrel-Cage Induction Machines}

\section{Gennadi Y. Sizov}

Department of Electrical and Computer Engineering, Marquette University, Milwaukee, WI Ahmed Sayed-Ahmed

Department of Electrical and Computer Engineering, Marquette University, Milwaukee, WI Chia-Chou Yeh

Powertrain Advanced Technology Center, General Motors Corporation, Torrance, CA Nabeel A. O. Demerdash

Department of Electrical and Computer Engineering, Marquette University, Milwaukee, WI 


\section{Abstract:}

In this paper, faults associated with the rotor of an induction machine are considered. More specifically, effects of adjacent and nonadjacent bar breakages on rotor fault diagnostics in squirrelcage induction machines are studied. It is shown that some nonadjacent bar breakages may result in the masking of the commonly used fault indices and, hence, may lead to a possible misdiagnosis of the machine. A discussion of the possible scenarios of these breakages as well as some conclusions regarding the types of squirrel-cage induction machines (number of poles, number of squirrel-cage bars, etc.) that may be more prone to these nonadjacent types of failures are presented. This discussion is supported through both simulation and experimental results. It is also shown that secondary fault effects can be used to diagnose such nonadjacent bar breakages.

\section{SECTION I. Introduction}

In recent years, condition monitoring as well as fault diagnostics of squirrel-cage induction machines received considerable attention from both industry and academia [1]-

[2][3][4][5][6][7][8][9][10][11][12][13][14][15][16][17][18][19][20][21][22][23]. A number of different techniques that address various types of the most common failures have been developed and implemented [1], [2]. Researchers were able to gain a better insight into the mechanisms of these failures and use this knowledge to both improve the design of the machine itself and develop the means to diagnose machine faults more effectively.

Induction machine failures are commonly divided, based on the main machine components, into three major groups, namely, bearing, stator, and rotor faults [3]-[4][5][6]. According to a number of independent studies described in [3]-[4][5][6], about $40 \%$ of faults associated with induction machines are due to bearing failures. Meanwhile, faults associated with stator windings account for another $40 \%$ of induction machine failures [3]-[4][5][6]. It should be highlighted that, although mechanisms of stator and bearing failures may differ slightly between different types of electric machines, these types of faults are known to be a common problem in other types of electric machines, namely, synchronous, brushless dc, reluctance, etc. Furthermore, failures associated with rotors account for approximately $10 \%$ of induction machine failures [3]-[4][5][6]. However, unlike bearing and stator faults, these faults are specific to squirrel-cage induction machines.

In general, there are three major types of faults that can be associated with squirrel-cage rotor structures, namely: 1) interlaminar currents, sometimes referred to as interbar currents caused by shorts through the rotor core laminations; 2) rotor end-ring connector breakages; and 3) rotor-bar breakages. These faults may result from a wide variety of stresses as well as manufacturing defects [7]-[8][9]. Frequent overloading, both thermal and electrical, as well as excessive vibrations due to supply voltage unbalances, load variations, and frequent starting transients may result in accelerated failures of squirrel-cage rotor bars and other structural components [8].

Interlaminar currents result from damage to the lamination insulation coating either during the manufacturing process or during the operation of the motor. These interlaminar currents typically result in excessive rotor heating, which may in turn lead to a rise in the overall motor temperature and hence stress other motor components, such as armature winding insulation and motor bearings. 
Moreover, during normal motor operation, interlaminar currents may account for as much as one-third of all stray load losses of the machine, hence resulting in reduced efficiency [10], [11].

Cracked or broken squirrel-cage bar or end-ring connector faults produce undesired torque oscillations (pulsations) that may result in undesired effects on the mechanical load, as well as induce undesired vibrations that may further stress other motor and load components [12].

In this paper, only broken squirrel-cage bar faults are addressed. More specifically, the effects of both adjacent and nonadjacent faults on two previously developed rotor fault diagnostic techniques [13][14][15][16][17][18][19][20][21][22] are studied. First, the spectral analysis of induction machine line currents, also known as motor current signature analysis (MCSA) [13]-[14][15][16][17][18], is used to diagnose various rotor faults. Second, the so-called magnetic field pendulous oscillation (MFPO) technique [19]-[20][21][22] is used to diagnose the same set of faults. It will be shown that some nonadjacent rotor-bar breakages result in the reduction of the fault indices of both the MCSA and MFPO techniques, hence significantly reducing chances of successful diagnosis of such faults. The problem of a complete breakage of one or more bars could develop in machines which are not monitored on a continuous basis, but are diagnosed/inspected at regularly scheduled maintenance intervals. In this case, a failure can go through an incipient stage to a complete breakage of one or more bars in the period between scheduled inspections. Hence, the possibility of nonadjacent bar failure exists and could pose a potential problem. Moreover, the likelihood of a nonadjacent fault is significantly increased in machines with a low number of rotor bars per pole, in which the number of bars between the breakages that would result in the fault masking effect is low. It will also be shown that secondary saturation effects that appear as a result of such nonadjacent rotor failures result in detectable oscillations of the rotor magnetic field at four times the slip frequency. Hence, these secondary saturation effects can be utilized for the diagnosis of such faults.

Including this introductory section, this paper is organized into six sections. In the second section, some basic considerations of squirrel-cage broken-bar faults are presented. Three fault scenarios are considered, namely, adjacent bar breakages, nonadjacent bar breakages separated by half a pole-pitch, and nonadjacent bar breakages separated by one pole-pitch. In the third section, a magnetic equivalent circuit (MEC) model, described in [24]-[25][26][27][28][29], is used to simulate a case-study 5-hp induction machine. In Section IV, two previously developed fault diagnostic techniques described in [13]-[14][15][16][17][18], [19]-[20][21][22] are reviewed, and their application to adjacent broken bar fault diagnostics is discussed. Also, in Section IV, the MEC model is used to verify the simple analysis presented in Section II. In Section V, experimental results of nonadjacent rotor faults, as well as the corresponding analysis and discussion of these results, are presented. Finally, conclusions and recommendations are presented in the last section.

\section{SECTION II. Rotor Fault Analysis}

\section{A. Healthy Rotor}

In this section, an intuitive/qualitative analysis of the effects of both adjacent and nonadjacent bar breakages on the magnetic field distribution of the induction machine is presented. Consider an elementary two-pole induction machine with a squirrel-cage rotor shown in Fig. 1(a). For simplicity of argument, an eight-bar squirrel-cage configuration is utilized in this analysis. Also, shown 
in Fig. 1(a) are the axes of the rotor current sheet represented by the rotating rotor current sheet vector $\vec{I}_{\text {cr }}$ and the rotor magnetomotive force represented by the rotating rotor MMF vector $\overrightarrow{\mathcal{F}}_{\text {mr }}$, in ampere-turns per pole. Shown in Fig. 1 (b) is the current sheet produced by the individual squirrel-cage bar currents. This current sheet rotates in space at synchronous speed $\omega_{\text {syn }}$, whereas the rotor is rotating at the rotor speed $\omega_{r}$. Hence, the relative speed between the rotor current sheet and the squirrel cage is equal to the slip speed. Accordingly, Fig. 1(a) and (b) shows a snapshot view of the current sheet and the rotor MMF position relative to the squirrel cage at a given time instant. As can be seen from Fig. 1(b), the current sheet axis is aligned with two bars carrying maximum positive and negative currents, at locations 3 and 7 , whereas the axis of the rotor MMF $\overrightarrow{\mathcal{F}}_{\mathrm{mr}}$ is $90^{\circ}$ behind the current sheet axis and is aligned with the bars carrying zero current, at locations 1 and 5 , respectively. There are two simplifying assumptions used throughout this section. First, the bar currents are sinusoidally time varying, resulting in a sinusoidally space-distributed current sheet. Second, there is no axial flux produced as a result of a bar breakage fault. In other words, the magnetic field is strictly 2-D, which means that the currents out of the bars and into the bars must sum to zero.

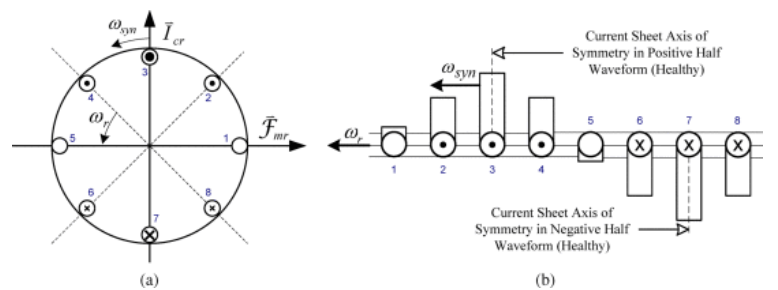

Fig. 1. Healthy rotor: (a) Eight-bar squirrel-cage rotor. (b) Rotor current sheet.

\section{B. Rotor with One Broken Bar}

Here, the effects of one broken bar on the current sheet and rotor MMF are considered. As one can see from Fig. 2(a), there are four possible locations 1, 3, 5, and 7 where a bar breakage will not result in any dislocation of the current sheet axis, and, hence, will not produce a rotor MMF reorientation. When the broken bar reaches location 1 or 5 , it does not result in any shift of the current sheet axis because the current that is supposed to be carried by the healthy bar at this location is negligible. Moreover, when the broken bar reaches location 3 or 7, it does not produce any axis shift due to the fact that the currents in the remaining (healthy) bars will redistribute to preserve the original healthy axis location. Accordingly, the remaining four locations of the bar breakage, namely, 2, 4, 6, and 8, will result in a current sheet axis shift which, in turn, will produce a shift in the rotor MMF axis. It should be noted that the fact that there are four instances in a slip cycle where the current sheet axis aligns with a healthy current sheet axis leads to the oscillation around the healthy axis at twice the slip frequency. Shown in Fig. 2(b) is the corresponding current sheet under the conditions of one broken rotor bar at a time instant when the broken bar reaches location 4. from Fig. 2(b) one should notice that, when the breakage reaches location 4 , it results in the shift of the so-called current sheet axis of symmetry in the positive half-waveform by the angle $\Delta \gamma$, which in turn results in the shift of both the overall current sheet and MMF axes by $\Delta \delta$. The maximum shift of the rotor MMF axis $\Delta \delta$ was defined in [19]$[20][21][22]$ as the swing angle and can be calculated through computation of voltage and current space vectors using standard line current and voltage measurements [19]-[20][21][22]. As was 
mentioned earlier, this shifting of the current sheet and MMF axes takes place four times during one slip cycle and reaches its maximum absolute value at four locations, namely, 2, 4, 6, and 8.
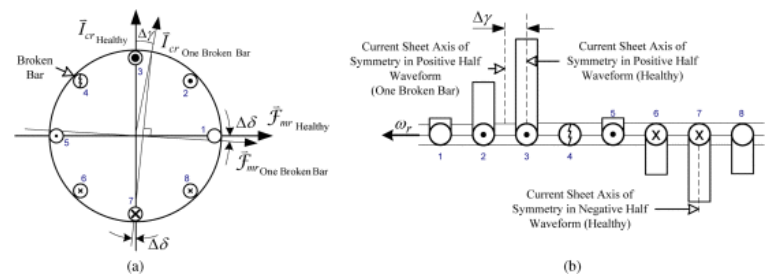

Fig. 2. One broken bar (broken bar at location 4): (a) Eight-bar squirrel-cage rotor. (b) Rotor current sheet.

\section{Rotor with Nonadjacent Bar Breakages}

Here, nonadjacent bar breakages are considered. More specifically, breakages separated by a half polepitch and one pole-pitch are studied, where a pole-pitch measure is considered to be equal to the number of rotor bars per pole. It is shown here that these two nonadjacent breakage scenarios represent two special cases that provide the basis for understanding the effects of other nonadjacent rotor-bar breakages on motor performance and the ease or difficulty in diagnosing such bar breakages.

\section{Half Pole-Pitch}

Here, the effects of two broken bars, separated by a half pole-pitch ( $90^{\circ}$ electrical), on the rotor current sheet and rotor MMF are considered. Using the example of the elementary eight-bar cage, the effects of two nonadjacent breakages separated by $90^{\circ}$ are shown in Fig. 3(a). At the time instant shown in Fig. 3, the broken bars are at locations 2 and 4 . As one can see from Fig. 3(a) and (b), the current sheet axis in the positive half-waveform in the case of two broken bars separated by half a pole-pitch is congruent with the current sheet axis in the positive half-waveform of the healthy case. Moreover, the axes of the current sheet and MMF will remain congruent with the axes of the healthy case throughout a slip cycle producing no detectable rotor MMF oscillation as a result of the fault, hence significantly reducing chances to successfully diagnose such a fault. This fault scenario represents the first special case of nonadjacent rotor faults. Moreover, chances of successful diagnosis, when the separation between the nonadjacent bar breakages approaches half pole-pitch, are significantly reduced. It should be noted that a similar masking effect on the fault indices of MCSA as well as on one of the model reference diagnostic techniques known as Vienna Method has been observed earlier in [2] and [23], respectively. However, no clear explanations of the causes of the fault masking effect have been presented.

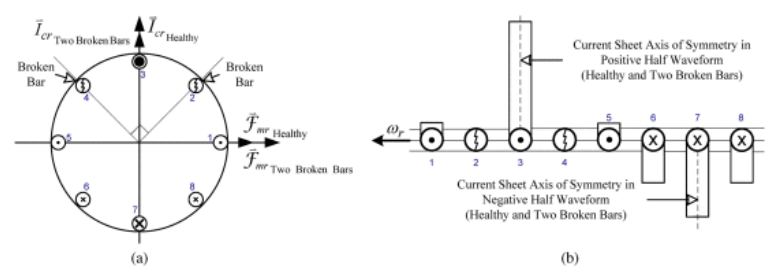

Fig. 3. Two broken bars half pole-pitch away (broken bars at locations 2 and 4): (a) Eight-bar squirrel-cage rotor. (b) Rotor current sheet. 


\section{One Pole-Pitch}

Here, the effects of two broken bars, separated by one pole-pitch ( $180^{\circ}$ electrical), on the rotor current sheet and rotor MMF are considered. As can be seen from Fig. 4, the current sheet symmetry axes in the positive and negative half-waveforms in the case of two broken bars separated by one pole-pitch are shifted by an angle $\Delta \gamma$ from the healthy axes, resulting in the overall shift of the rotor MMF. Hence, two breakages separated by one pole-pitch will result in the oscillation of the rotor MMF with a maximum value of the swing angle equal to $\Delta \delta=\Delta \gamma$. It can also be shown that this shift is identical to the shift produced by the two adjacent bar breakages, hence resulting in the same values of fault indices. This fault scenario represents the second special case of nonadjacent rotor faults. In the case when the separation between the nonadjacent bar breakages approaches one pole-pitch, the rotor MMF appears to be disturbed in the same way as in the case of an adjacent fault. Accordingly, from this simple analysis, it appears that there will be no masking effect manifested in the case when bar breakages are separated by a complete pole-pitch.

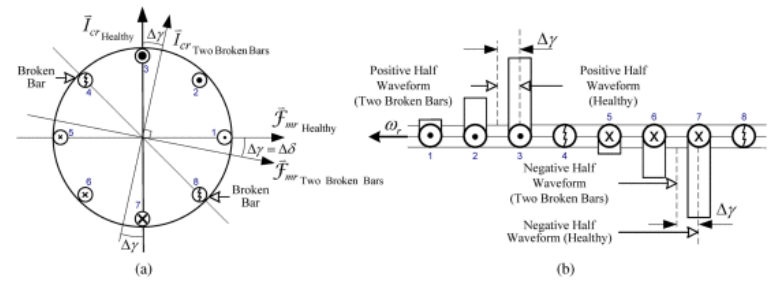

Fig. 4. Two broken bars one pole-pitch away (broken bars at locations 4 and 8): (a) Eight-bar squirrel-cage rotor. (b) Rotor current sheet.

In summary, this section presented a simple analysis that can be used to visualize effects produced by rotor-bar breakages on the squirrel-cage rotor spatial current distribution and the corresponding rotor MMF. It should be stressed that this simple qualitative approach to rotor fault visualization resulted from extensive fault simulation using MEC models and time-stepping finite-element (TSFE) analysis. Moreover, from the analysis previously presented, it should be observed that a rotor-bar breakage results in a slight reduction of the magnitude of rotor MMF; however, more importantly, it results in the oscillation of the rotor MMF, which in turn, produces the detectable magnetic field disturbance. This field disturbance may manifest itself in a number of ways that can be used to detect such a fault. More specifically, it reflects itself in the stator currents by modulating the amplitudes of line currents. It also produces detectable torque oscillations, which may, in turn, result in consequent speed oscillations.

\section{SECTION III. MEC Approach to Induction Machine Modeling}

In this section, the development of the MEC model for fault simulation studies is briefly discussed. The MEC modeling approach has been successfully used to model a variety of electric machines under various healthy and faulty conditions [24]-[25][26][27][28].

The MEC model allows one to incorporate space harmonics due to discrete winding distribution, stator and rotor slotting, as well as the saliency effect caused by the saturation of the magnetic material [24][25][26][27]. Moreover, the deep-bar effect, also known as the skin effect, can be included in the solution to provide a more realistic transient model of the machine [24]. The MEC model provides reasonably accurate results and relatively small computation time, when compared to the TSFE model. 
Finite-element models, in general, provide a higher degree of space discretization and, hence, a more accurate solution, when compared to the MEC approach. However, the computational time required by a finite-element model is significantly increased due to its complexity.

A case-study 5-hp 60-Hz 6.8-A 1165-r/min 0.777-p.f. squirrel-cage induction machine with 36 stator slots and 45 rotor slots has a double-layer stator winding with the layout shown in Table I. In Table I, "Outer" refers to the part of the stator slot closest to the air gap, whereas "Inner" refers to the part of the slot closest to the backiron/yoke. Moreover, this machine has two slots per pole per phase, a total of 36 coils with 20 turns per coil. 
Table I Stator Winding Layout of 5-hp Squirrel-Cage Induction Machine

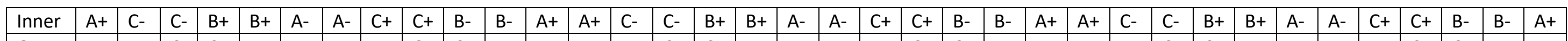

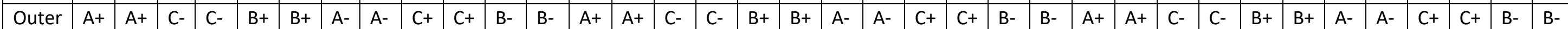

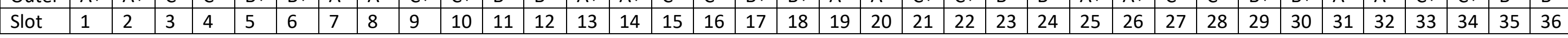

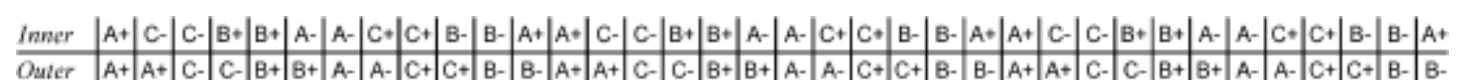

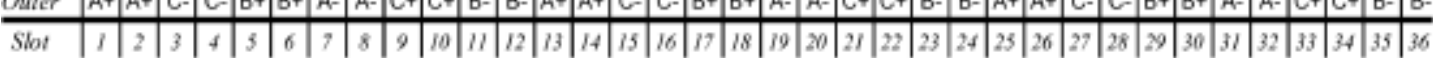


A stator slot with a double-layer winding, such as the one shown in Table I, can be represented by a simplified MEC [24] shown in Fig. 5(a). In this magnetic circuit representation of the stator slot, it is assumed that the magnetic flux can flow in either of the two directions, namely, radial and/or tangential. Meanwhile, MMF sources $\mathcal{F}_{S}$ are placed in the stator teeth in order to represent the effect of the current-carrying coil sides. Also, the reluctance values representing the regions of the stator where the magnetic material is present, namely, $\mathfrak{R}_{S_{\text {TоОтн }}}$ and $\mathfrak{R}_{S_{\text {YOKE }}}$ of Fig. 5(a), can be varied depending on the value of the flux density. Therefore, varying these reluctances, depending on the value of the flux density, enables one to capture, in the solution, the effects of the local saturation of the magnetic material in the stator teeth. In this MEC representation of the stator slot, stator teeth and backiron/yoke are characterized by single reluctance values, namely, $\mathfrak{R}_{S_{\text {Tоотн }}}$ and $\mathfrak{R}_{S_{\text {YOKE' }}}$ respectively. Meanwhile, tangential slot leakage reluctances are lumped into a single reluctance value $\mathfrak{R}_{S_{\text {TAN }}}$. Here, it should be mentioned that the stator slot tangential leakage reluctance $\mathfrak{R}_{S_{\text {TAN }}}$ is a function of the slot geometry only and, hence, will remain constant during the operation of the machine. Also, it should be noted that index $m$ is used here to distinguish between the individual stator tooth reluctances, which may vary from tooth to tooth if saturation needs to be considered. Assuming a steady-state operation of the machine, the rotor slot can be modeled as shown in Fig. 5(b). It should be highlighted that the MEC modeling approach can be utilized for various transient simulations if the rotor slot is divided into a sufficient number of sections [24]. Another approach of including the deepbar (skin) effect in the solution is by updating the reactance of the rotor bar (depending on the rotor speed) at every time step of the simulation.

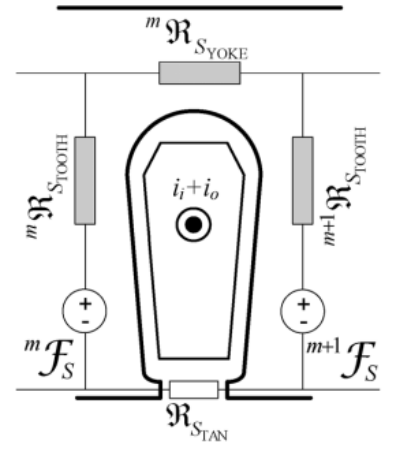

(a)

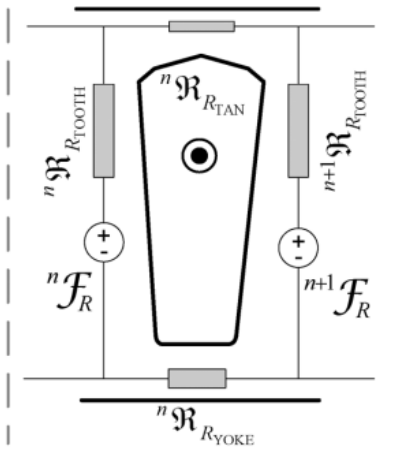

(b)

Fig. 5. Simplified MEC representation of (a) double-layer stator winding and (b) rotor slot (without deep-bar effect).

Now that both the stator and rotor slot MECs are defined, a complete MEC model of the induction machine can be assembled. This model is shown in Fig. 6. In this figure, air-gap reluctances are included to provide the coupling between the rotor and the stator teeth. It should be noted that electromechanical energy conversion takes place in the air gap; hence, it is crucial to model the air-gap reluctances as accurately as possible. Moreover, from Fig. 6, it should be noted that the MEC model is assembled such that every tooth on the stator is coupled to every tooth on the rotor and vice versa. Air-gap reluctances depend on the relative position of the corresponding stator and rotor teeth. Hence, the value of the air-gap reluctance is a function of geometry (relative position of the rotor with respect to the stator). More specifically, an air-gap reluctance is a function of the area of overlap of stator and rotor teeth. To avoid possible numerical difficulties in a computer simulation associated with 
possibilities of dealing with infinite air-gap reluctances, one should invert the reluctance values to obtain the corresponding permeance values. from Fig. 6, one can proceed with the development of the system of algebraic equations. The nodal-potential method can be used to generate the required equations. The nodes used to generate the equations are $\mathcal{F}_{1_{(\mathrm{m})}}, \mathcal{F}_{2_{(\mathrm{m})}}, \mathcal{F}_{3_{(\mathrm{n})}}$, and $\mathcal{F}_{4_{(\mathrm{n})}}$, where the index $m$ identifies a stator tooth and the index $n$ is used to identify a specific rotor tooth. Hence, in the case-study motor with $N_{S}=36$ stator slots and $N_{R}=45$ rotor slots, the index $m$ varies from 1 to 36 and the index $n$ varies from 1 to 45 . Considering Fig. 6 with the reluctances substituted with the corresponding permeances, one can develop four sets of nodal equations as follows:

$$
\left[\begin{array}{cccc}
\underline{\mathbf{A}}_{11} & \underline{0} & \underline{0} & \underline{0} \\
\underline{0} & \underline{\mathbf{A}}_{22} & \underline{\mathbf{A}}_{23} & \underline{0} \\
\underline{0} & \underline{\mathbf{A}}_{32} & \underline{\mathbf{A}}_{33} & \underline{0} \\
\underline{0} & \underline{0} & \underline{0} & \underline{\mathbf{A}}_{44}
\end{array}\right]\left[\begin{array}{l}
\underline{F}_{1} \\
\underline{F}_{2} \\
F_{3} \\
\underline{F}_{4}
\end{array}\right]=\left[\begin{array}{c}
-\underline{\boldsymbol{\Phi}}_{S} \\
\underline{\boldsymbol{\Phi}}_{S} \\
-\underline{\boldsymbol{\Phi}}_{R} \\
\underline{\boldsymbol{\Phi}}_{R}^{\prime}
\end{array}\right]
$$

where the vector of rotor tooth fluxes $\underline{\Phi}_{R}^{\prime}$ is expressed as follows:

$$
\underline{\Phi}_{R}^{\prime}=\left[\begin{array}{lllll}
\Phi_{\mathrm{R}_{(1)}} & \Phi_{\mathrm{R}_{(2)}} & \Phi_{\mathrm{R}_{(3)}} & \cdots & \Phi_{\mathrm{R}_{\left(N_{R-1}\right)}}
\end{array}\right]^{\mathrm{T}} .
$$

In order to provide a relationship between the nodal MMF vectors $\underline{\mathcal{F}}_{1}, \underline{\mathcal{F}}_{2}, \underline{\mathcal{F}}_{3}$, and $\underline{\mathcal{F}}_{4}$ and the corresponding individual stator and rotor tooth MMF vectors $\underline{\mathcal{F}}_{S}$ and $\underline{\mathcal{F}}_{R}$, produced by the currentcarrying coil sides, two additional sets of equations have to be introduced. from Fig. 6, these can be derived as follows:

$$
\begin{aligned}
& F_{S}=\underline{F_{2}}-\underline{F}_{1}+\underline{\Re}_{S} \underline{\boldsymbol{\Phi}}_{S} \\
& \underline{F}_{R}=\underline{F}_{3}-\underline{F}_{4}^{\prime}-\underline{\mathfrak{R}}_{R} \underline{\boldsymbol{\Phi}}_{R}
\end{aligned}
$$

where $\underline{\mathcal{F}}_{4}^{\prime}=\left[\mathcal{F}_{4_{(1)}} \mathcal{F}_{4(2)} \mathcal{F}_{4(3)} \cdots \mathcal{F}_{4\left(N_{R}-1\right)} 0\right]^{\mathrm{T}}$. Also, $\underline{R}_{S}$ and $\underline{\Re}_{R}$ are the diagonal matrices of the stator and rotor tooth reluctances.

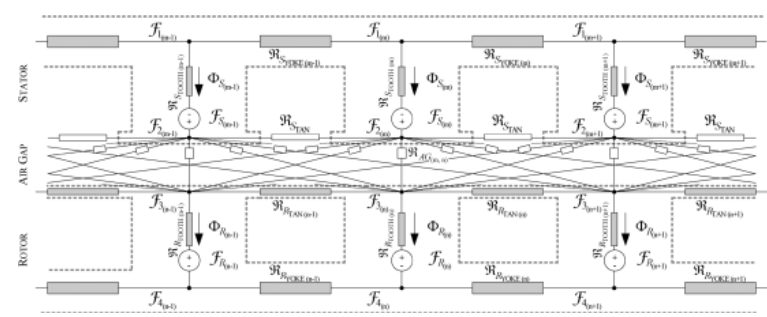

Fig. 6. MEC representation of the 5-hp induction machine (with closed rotor slot).

In order to derive a relationship between the stator phase flux linkages $\lambda_{a}, \lambda_{b}$, and $\lambda_{c}$ and the individual stator tooth fluxes $\underline{\Phi}_{S}$ and the stator line currents $i_{a}, i_{b}$, and $i_{c}$ and the individual tooth 
MMFs $\mathcal{F}_{S}$, one has to consider the stator winding layout provided in Table I. An analytical approach to developing a relationship between the stator phase flux linkages and individual stator tooth fluxes based on parameters such as the type of the winding, the number of slots, the number coils per phase per pole, the winding connection, etc., has been developed in [24]. For this case-study 5-hp squirrelcage induction machine, with double-layer winding provided in Table I, these relationships are provided in

$$
\begin{aligned}
& \underline{\boldsymbol{\lambda}}_{a b c}=\underline{\mathbf{w}}^{\prime} \underline{\boldsymbol{\Phi}}_{S} \\
& \underline{F}_{S}=\underline{\mathbf{w}}^{\prime \prime} \underline{\mathbf{i}}_{a b c}
\end{aligned}
$$

(5)(6)

where $N$ is the number of turns per coil and $\underline{\mathbf{w}}^{\prime}$ and $\underline{\mathbf{w}}^{\prime \prime}$ have been defined as flux and MMF connection matrices in [24]. For the squirrel-cage rotor, the procedure is greatly simplified. In a squirrel-cage rotor, the tooth fluxes $\underline{\Phi}_{R}$ are equal to the rotor loop flux linkages $\underline{\lambda}_{R}$. Meanwhile, rotor tooth MMFs $\underline{F}_{R}$ can be assumed equal to the rotor loop currents $\underline{\mathbf{i}}_{R}$. The expression for electromagnetic torque can be derived, based on electromechanical energy conversion principles, from the MEC model directly [24] and is given as follows:

$$
T_{\mathrm{em}}=\frac{1}{2} \sum_{m=1}^{N_{S}} \sum_{n=1}^{N_{R}}\left(F_{2_{(m)}}-F_{3_{(n)}}\right)^{2} \frac{d P_{\mathrm{AG}_{(m, n)}}}{d \theta_{R}}
$$

\section{(7)}

where $\theta_{R}$ is the rotor position in mechanical measure.

A block diagram of a complete MEC model coupled to the electrical and mechanical systems is shown in Fig. 7. In Fig. 7, one should note the lack of a minus sign in the expression of the rotor flux linkage. This is because of the orientation of the positive direction of flux adopted throughout the model, resulting in the lack of the minus sign in the global model.

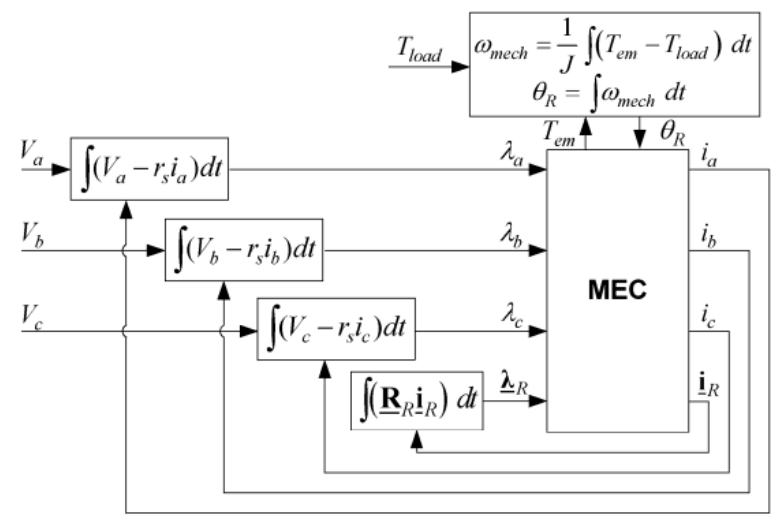

Fig. 7. Block diagram of a complete squirrel-cage induction machine MEC model. 
The parameters of the MEC model are provided in Table II. It should be noted that, if the saturation of the magnetic material does not need to be considered, the value of relative permeability $\mu_{R}=$ 11000 in the linear region of the B-H curve can be used for permeance calculations. The developed MEC model of a case-study 5-hp induction machine has been verified with respect to both the TSFE model simulations and experimental tests for various healthy and faulty conditions [29]. The results obtained from the simulations of the MEC model have been found to be in good agreement with both the TSFE model and the experimental tests [29]. Further MEC model validation is presented in the following section.

Table II Relevant MEC Model Parameters

\begin{tabular}{|l|l|l|}
\hline PARAMETER & STATOR & ROTOR \\
\hline Stator Resistance, $r_{s},[\Omega /$ phase $]$ & 1.34 & \\
\hline Rotor bar resistance, $r_{b}[\mu \Omega]$ & & 57.1 \\
\hline Ring resistance bar-to-bar $, r_{e r},[\mu \Omega]$ & & 3.20 \\
\hline Tooth reluctance, $\mathfrak{N},\left[\mathrm{H}^{-1}\right]$ & $\left(2.71 \times 10^{7}\right) / \mu \mathrm{R}$ & $\left(2.69 \times 10^{7}\right) / \mu \mathrm{R}$ \\
\hline Tangential permeance, $P_{T A N},[\mathrm{H}]$ & $4.44 \times 10^{-7}$ & $2.70 \times 10^{-7}$ \\
\hline Yoke/backiron permeance, $P_{Y O K E},[\mathrm{H}]$ & $1.27 \times 10^{-3}$ & $1.20 \times 10^{-2}$ \\
\hline Maximum value of air-gap permeance, $P_{A G \mathrm{MAX}},[\mathrm{H}]$ & $4.21 \times 10^{-6}$ & \\
\hline
\end{tabular}

$\mu_{R}=$ relative permeability

\section{SECTION IV. Diagnostics Techniques}

In this section, two diagnostic techniques that have been previously established in the literature are summarized. Both of these techniques have proven to be reliable for diagnostics of adjacent rotor-bar breakages. The main purpose of this section is to establish the necessary background required for rotor fault analysis that will follow in the next section. Hence, this section will concentrate on the basic application of these techniques to rotor fault diagnostics in squirrel-cage induction machines.

\section{A. Motor Current Signature Analysis (MCSA)}

The spectrum analysis of induction machine line currents, also known as MCSA, is one of the most commonly used rotor fault diagnostic techniques [13]-[14][15][16][17][18]. In this technique, sidebands adjacent to the supply fundamental frequency component, present in the frequency spectrum of motor currents, are used to diagnose the extent of the fault. As has been shown in Section II, in the case of a broken bar fault, the magnetic field produced by the rotor will oscillate at twice the slip frequency $2 s f_{\text {syn. }}$. According to Faraday's Law, this oscillating magnetic field will induce an electromotive force (EMF) in the stator windings, which in turn, will result in the stator current component at the same $2 s f_{\text {syn }}$ frequency. However, since the magnetic field produced by rotor currents is also moving in space at synchronous speed, it will also induce an EMF and a consequent current at synchronous frequency $f_{\text {syn }}$. Moreover, since, in the motoring region, the squirrel-cage rotor structure is moving at a speed lower than synchronous, the resulting stator EMF and the corresponding stator current will have a component at a frequency equal to $\left(f_{\text {syn }}-2 s f_{\text {syn }}\right)=f_{\text {syn }}(1-2 s)$. This $f_{\text {syn }}(1-2 s)$ frequency component in the stator current spectrum can be used for rotor fault diagnostic purposes and is usually referred to as the lower sideband (LSB) component. Shown in Figs. 8 and 9 are the stator line current spectra under healthy and one-broken-rotor-bar conditions. 
One should notice the lack of a distinguishable LSB component in the line current spectrum of the healthy machine. On the other hand, in the case of one broken bar, there is a detectable LSB component. Moreover, as one can see from Fig. 9, there is an additional component at a frequency equal to $f_{\text {syn }}(1+2 s)$. This $f_{\text {syn }}(1+2 s)$ is the so-called upper sideband (USB) component. The existence of this frequency component can be traced back to the LSB component. In other words, the current component at $f_{\text {syn }}(1-2 s)$ produces a consequent torque pulsation at twice the slip frequency $2 s f_{\text {syn. }}$. This torque pulsation may, in turn, result in the consequent speed pulsations at the same frequency $2 s f_{\text {syn, }}$ which will produce a component in the stator current at $f_{\text {syn }}(1+2 s)$. This process of interaction of stator current harmonics, torque oscillation, and the consequent speed ripple will continue to induce stator current harmonics at $(1 \pm k s) f_{\text {syn }}$ (where $k=2,4,6$...). However, the existence of a detectable speed ripple and the consequent USB component is not guaranteed in cases where the total inertia of the motor-load system is high. This dependence of the magnitude of the USB component on the motor-load inertia has been studied in detail in [15] and [22].

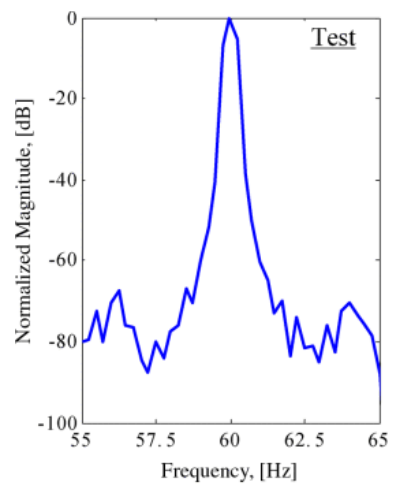

(a)

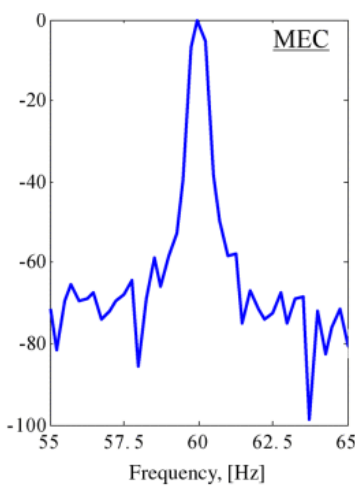

(b)

Fig. 8. Stator line current spectrum of 5-hp induction machine under healthy full-load conditions (30 Nm, 1165 $\mathrm{r} / \mathrm{min}$ ): (a) Experimental test. (b) MEC model supplied with measured voltages.

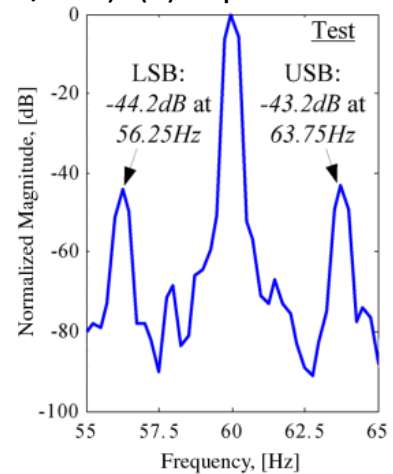

(a)

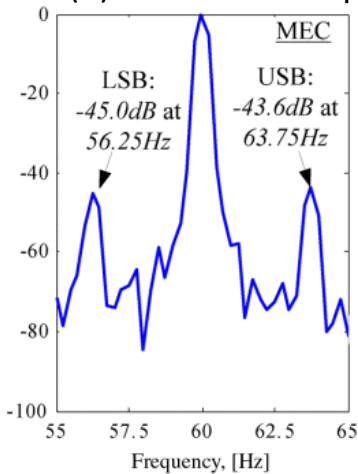

(b)

Fig. 9. Stator line current spectrum of 5-hp induction machine under one-broken-bar full-load conditions (30 $\mathrm{Nm}, \sim 1165 \mathrm{r} / \mathrm{min}$ ): (a) Experimental test. (b) MEC model supplied with measured voltages.

\section{B. Magnetic Field Pendulous Oscillation (MFPO)}

A so-called MFPO technique, where time-domain values of motor line currents and voltages are used to generate the corresponding space vectors and the oscillation of the angle between these space vectors is used as the fault index, has been introduced in [19]-[20][21][22]. Again, referring back to Section II, where it has been shown that a broken bar results in the oscillation of the rotor MMF 
around its healthy axis at twice the slip frequency $2 s f_{\text {syn }}$, one can take a different approach from that chosen in the MCSA analysis. Considering the overall effect of the rotor fault on the resultant magnetic field distribution in the machine, one can deduce that the oscillation of the rotor MMF will result in a corresponding oscillation of the stator and rotor resultant MMF. As has been shown in [19][20][21][22], this oscillation of the resultant MMF can be observed by monitoring the position of the stator current space vector $\vec{i}_{s}(t)$. More specifically, the relative motion of the stator current space vector $\vec{i}_{s}(t)$ with respect to the stator voltage space vector $\vec{v}_{s}(t)$ can be used for diagnostics purposes [19]-[20][21][22]. Using three voltage and current measurements, stator current and voltage space vectors can be calculated as follows [19]-[20][21][22]:

$$
\begin{aligned}
\vec{i}_{s}(t)= & \frac{2}{3}\left(\left(i_{a}(t)-i_{b}(t)\right)+\alpha\left(i_{b}(t)-i_{c}(t)\right)\right. \\
& \left.+\alpha^{2}\left(i_{c}(t)-i_{a}(t)\right)\right) \\
\vec{v}_{s}(t)= & \frac{2}{3}\left(v_{a b}(t)+\alpha\left(v_{b c}(t)\right)+\alpha^{2}\left(v_{c a}(t)\right)\right)
\end{aligned}
$$

(8)(9)

where $\alpha$ is the complex space-vector operator provided in

$$
\alpha=e^{j \frac{2 \pi}{3}}
$$

Meanwhile, the pendulous oscillation angle $\delta(t)$ is defined in [19]-[20][21][22] as the angle between the current and voltage space vectors can be expressed as follows:

$$
\delta(t)=\angle \vec{i}_{s}(t)-\angle \vec{v}_{S}(t)
$$

Furthermore, $\delta_{1}(t)$ is the fundamental component of the pendulous oscillation, and the swing angle $\Delta \delta_{1}$ is the peak-to-peak value of the fundamental component of pendulous oscillation $\delta_{1}(t)$. In this diagnostics technique, the swing angle $\Delta \delta_{1}$ is considered as the fault index which can be used to diagnose the extent of the fault. Here, the swing angle $\Delta \delta_{1}$ is similar to the LSB component of the MCSA diagnostics approach in the sense that both LSB and swing angle $\Delta \delta_{1}$ are used as fault indices.

The pendulous oscillation is a time-domain phenomenon and, hence, can be easily correlated with the physical processes taking place in the machine during the fault. Here, this property of the MFPO will be used to further verify the simplified analysis presented in Section II, as well as to gain a better understanding of the effects of the fault. In Section II, it has been stated that the highest distortion of rotor MMF axis occurs at time instants when the breakage reaches the locations halfway between the bar carrying the maximum absolute value of the current and the bar carrying no current. In other words, when the breakage is $45^{\circ}$ (electrical) from the bar carrying the maximum absolute value of the 
current, the breakage has the largest impact on the orientation of the rotor MMF axis. In the simple eight-bar squirrel-cage rotor of Section II, considering Fig. 2(a) and (b), these locations of maximum MMF disturbance are 2, 4, 6, and 8 . It has also been stated that the rotor fault does not have any effect on the rotor MMF orientation at time instants where the broken bar is supposed to carry the maximum absolute value of the current, as well as at locations where it is supposed to carry no current. Again, considering Fig. 2(a) and (b), the locations of bar breakage, which will not have any effect on the location of the rotor MMF axis and the machine will appear as if healthy, are locations 1, 3, 5, and 7. This means that, at time instants when the breakage reaches locations $1,3,5$, and 7 , the value of the pendulous oscillation angle $\delta(t)$ should correspond/intersect with that of the healthy case.

Now, in order to verify the analysis presented in Section II, consider a time-domain profile of pendulous oscillation angle $\delta(t)$ under the condition of one broken rotor bar obtained from the MEC simulation of the case-study 5-hp induction machine. This time-domain profile of pendulous oscillation is shown over a complete slip cycle in Fig. 10. As has been previously mentioned in the case of a onebroken-bar fault, the pendulous oscillation has a frequency equal to twice the slip frequency $2 s f_{\text {syn }}$. Consequently, as can be observed from Fig. 10, there are four time instances in a slip cycle where the pendulous oscillation angle reaches its maximum absolute value. Considering Fig. 10, these time instances are $t_{1}, t_{3}, t_{5}$, and $t_{7}$. Moreover, there are four time instances in a slip cycle where the bar breakage does not have any effect on the orientation of the rotor MMF. In other words, there are four time instances in a slip cycle where the axis of the faulty rotor MMF aligns with the axis of the healthy MMF. In Fig. 10, these time instances are labeled as follows: $t_{2}, t_{4}, t_{6}$, and $t_{8}$. In order to verify the analysis previously presented, consider the current sheet distributions at time instances $t_{1}$ to $t_{8}$ shown in Fig. 11(a)-(h), respectively. These current sheet distributions are readily available from both the MEC and the TSFE simulations but are rather difficult to obtain in an experimental setting. Therefore, here in Fig. 11(a)-(h), only MEC simulation results are presented. Moreover, it should be mentioned that, in Fig. 11, bar number "12" is assumed to be broken.

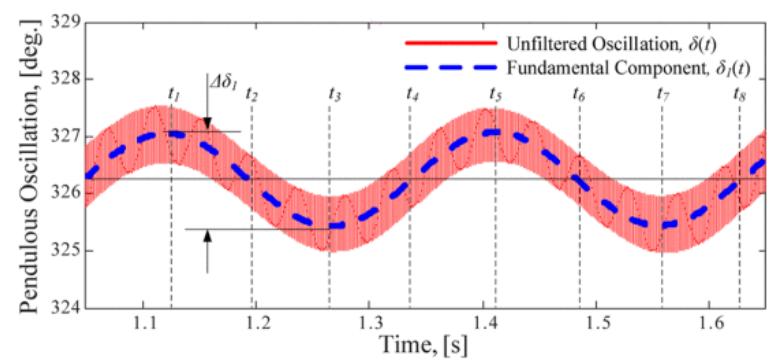

Fig. 10. Pendulous oscillation time-domain profile over one slip cycle (one-broken-bar full-load (30 Nm, 1165 $\mathrm{r} / \mathrm{min}$ ) MEC simulation). 


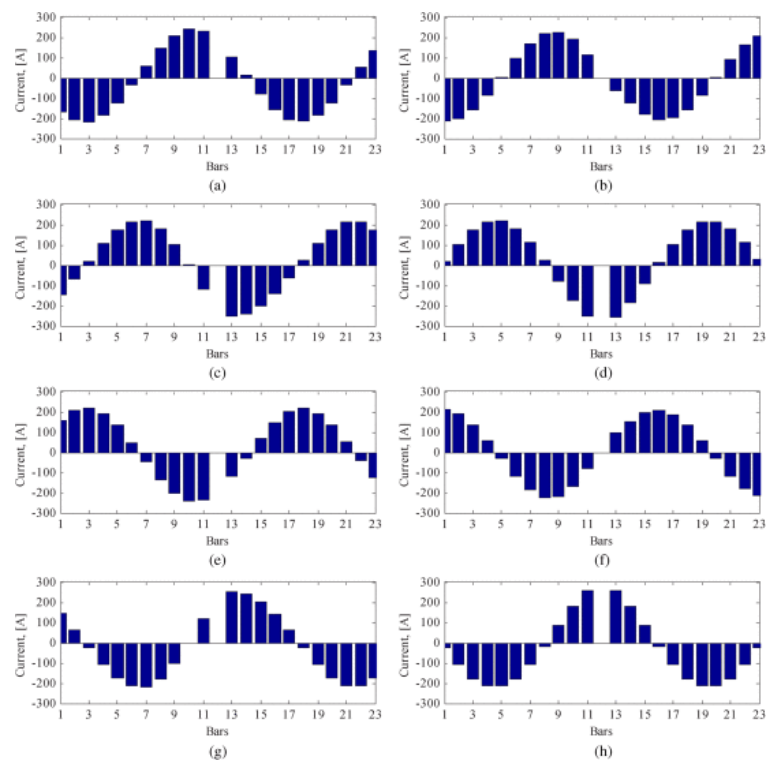

Fig. 11. Rotor current sheet profiles at various time instants (shown in Fig. 10) during one slip cycle (bar\#12 broken, MEC simulation). (a) Rotor current sheet at time instant $t_{1}$. (b) Rotor current sheet at time instant $t_{2}$. (c) Rotor current sheet at time instant $t_{3}$. (d) Rotor current sheet at time instant $t_{4}$. (e) Rotor current sheet at time instant $t_{5}$. (f) Rotor current sheet at time instant t6. (g) Rotor current sheet at time instant $t_{7}$. (h) Rotor current sheet at time instant $t_{8}$.

As can be seen from the pendulous oscillation profile of Fig. 10 and the corresponding current sheet profiles shown in Fig. 11(a)-(h), the simple analysis presented in Section II is indeed valid and, hence, can be used to visualize the effects of such rotor faults. In addition, from Fig. 11, one should notice that magnitudes of bar currents immediately adjacent to the fault are not significantly increased. In this 5$\mathrm{hp}$ machine, the increase in the bar-current magnitudes of the bars immediately adjacent to the fault is approximately $22 \%$, when compared to the healthy bar-current magnitudes under the same load conditions.

\section{SECTION V. Experimental Results}

In this section, the experimental results for a number of nonadjacent bar breakage scenarios are considered. In the first part of this section, experimental results for nonadjacent bar breakages separated by one-half pole-pitch ( $90^{\circ}$ electrical) are considered. Meanwhile, in the second part of this section, rotor faults separated by one complete $\left(180^{\circ}\right.$ electrical) pole-pitch are studied. As has been mentioned in Section II, in this paper, a pole-pitch measure is considered to be the number of rotor bars per pole. For the case-study 5-hp machine (45 bars, six poles) used in this paper, this number is fractional and equal to $71 / 2$ bars per pole. It should also be mentioned that the experimental results presented in this section were obtained at rated operating conditions with the machine supplied by a balanced three-phase sinusoidal voltage supply. For this case-study 5-hp machine, rated conditions correspond to a torque of $30 \mathrm{Nm}$ at a shaft speed of $1165 \mathrm{r} / \mathrm{min}$.

\section{A. Rotor-Bar Breakages Separated by Half Pole-Pitch}

Here, experimental results of the machine operating under conditions of broken bars separated by a half pole-pitch $\left(90^{\circ}\right.$ electrical) are presented. The results are evaluated using the two diagnostic 
techniques, namely, MCSA and MFPO [13]-[14][15][16][17][18][19][20][21][22]. Two fault scenarios are considered, namely, two broken bars separated by one-half pole-pitch and $N_{b}$ broken bars each separated by one-half pole-pitch from the other, where $N_{b}$ is an integer.

\section{Two Broken Bars Separated by Half Pole-Pitch}

As has been previously shown in Section II, such faults are difficult to diagnose because of the fault masking that takes place when two bars are separated by one-half pole-pitch ( $90^{\circ}$ electrical). However, as will be shown in this section, these nonadjacent faults can still be diagnosed using secondary saturation effects that appear under such fault conditions.

Shown in Fig. 12(a) is the cross section of the case-study machine showing the locations of nonadjacent rotor-bar breakages separated by approximately one-half pole-pitch ( $90^{\circ}$ electrical). Shown in Fig. 13(a) are the experimental results evaluated using the MCSA diagnostic technique. Also, for purposes of comparison, shown in Fig. 13 are the results for healthy and two adjacent bar breakage cases. from Fig. 13, one should notice that both LSB and USB components at frequencies equal to ( $1 \pm$ $2 s) f_{\text {syn }}$ are significantly reduced in the case of the nonadjacent fault. Hence, when the original MCSA approach is used to diagnose this type of fault, the chances of successful diagnosis of the machine under such nonadjacent bar breakage are significantly reduced. Moreover, upon careful examination of Fig. 13, one should notice that, in the case of the nonadjacent fault, the LSB component at a frequency equal to $(1-2 s) f_{\text {syn, }}$ which is generally used as the primary fault index in the MCSA approach, corresponds to the LSB of the healthy machine.
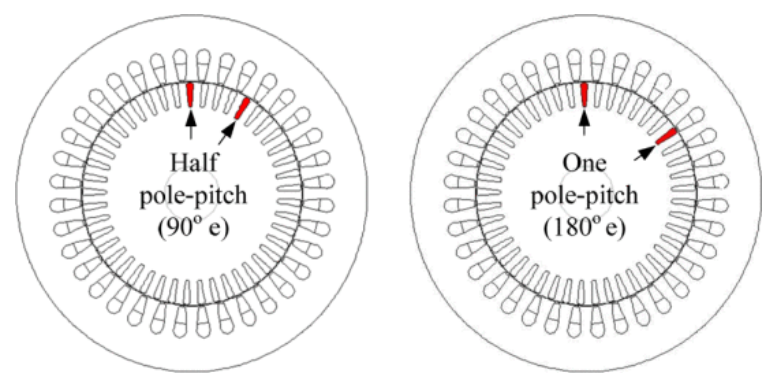

Fig. 12. Cross section of a case-study 5-hp squirrel-cage induction machine showing locations of nonadjacent bar breakages separated by (a) half pole-pitch and (b) one pole-pitch.

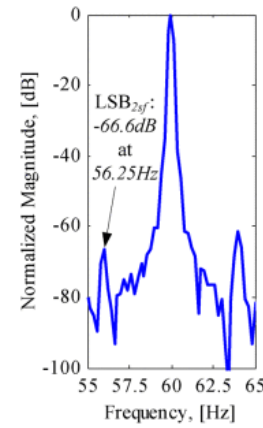

(a)

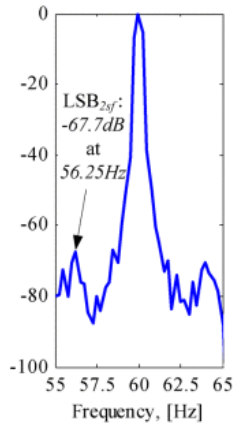

(b)

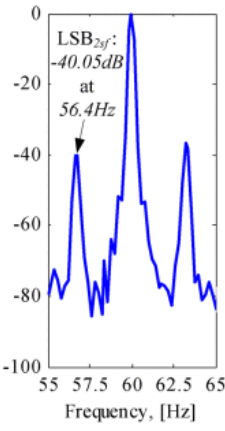

(c)

Fig. 13. Current frequency spectrum (MCSA): (a) Two broken bars separated by half pole-pitch, $90^{\circ}$ electrical. (b) Healthy conditions. (c) Two adjacent broken bars. Experimental tests (30 Nm, 1165 r/min).

In Fig. 14, the same experimental results are evaluated using the MFPO technique. In these figures, the time-domain profiles of pendulous oscillation are plotted over a time period equal to approximately 


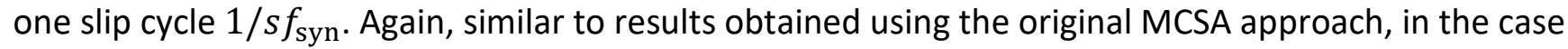
of a nonadjacent rotor fault, the swing angle fault index $\Delta \delta_{1}$ is significantly reduced. One should also notice that the frequency of the pendulous oscillation doubles in the case of the nonadjacent rotor fault. Consequently, referring back to the frequency spectrum of the MCSA approach (Fig. 13) in the case of the nonadjacent rotor-bar breakage fault, one should expect detectable sidebands at

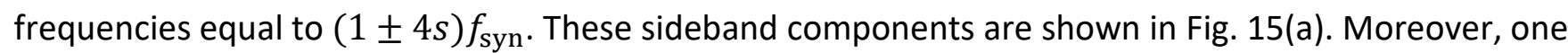
should also notice the lack of these components in the frequency spectra of the healthy machine [Fig. 15(b)] and the machine with two adjacent bar breakages [Fig. 15(c)]. This alludes to the fact that, in the case when the classic LSB component at $(1-2 s) f_{\text {syn }}$ is not present, one could use the LSB component at $(1-4 s) f_{\text {syn }}$ to detect such nonadjacent faults. It should be mentioned that, in the case of adjacent bar breakage faults, sideband components at $(1 \pm 2 s) f_{\text {syn }}$ may result in other sideband components including sidebands at $(1 \pm 4 s) f_{\text {syn. }}$. However, in the case of nonadjacent rotor faults separated by one-half pole-pitch, the $(1 \pm 4 s) f_{\text {syn }}$ components appear due to secondary local rotor saturation effects adjacent to the location of these breakages. In the case of a broken rotor bar, the rotor teeth immediately adjacent to the broken bar are subjected to higher flux densities which, in turn, locally affect the magnetic core permeability in these teeth. This results in the local saturation patterns that appear twice every slip cycle. Moreover, in the case of two nonadjacent bar breakages, this will result in saturation patterns appearing four times during one slip cycle. Consequently, these patterns modulate the stator currents and/or produce torque pulsations, which in turn, may result in consequent speed oscillation and hence lead to subtle but detectable fault indices.

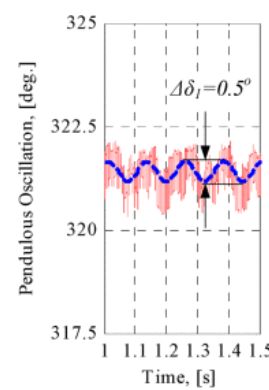

(a)

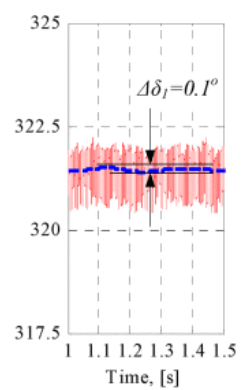

(b)

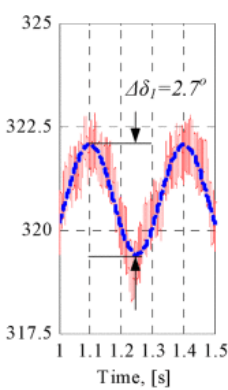

(c)

Fig. 14. Pendulous oscillation time-domain profile (MFPO): (a) Two broken bars separated by half pole-pitch, $90^{\circ}$ electrical. (b) Healthy conditions. (c) Two adjacent broken bars. Experimental tests (30 Nm, 1165 r/min).

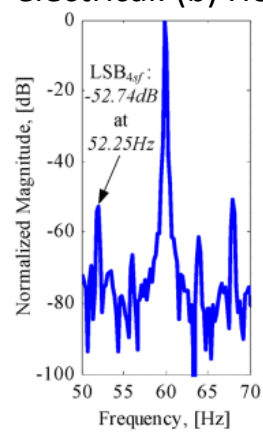

(a)

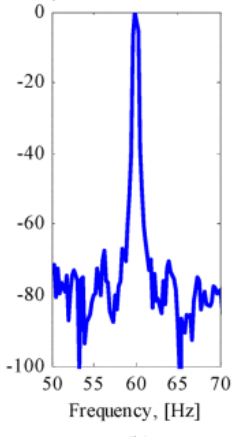

(b)

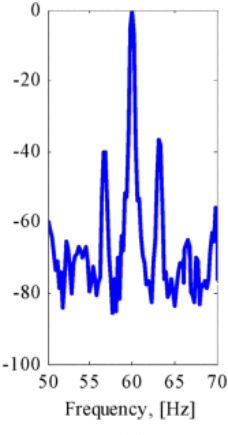

(c)

Fig. 15. Current frequency spectrum (MCSA expanded frequency axis of Fig. 13): (a) Two broken bars separated by half pole-pitch, $90^{\circ}$ electrical. (b) Healthy conditions. (c) Two adjacent broken bars. Experimental tests $(30 \mathrm{Nm}, \sim 1165 \mathrm{r} / \mathrm{min})$. 


\section{2. $N_{b}$ Broken Bars Separated by Half Pole-Pitch}

In the previous section, it has been shown that two broken bars separated by one-half polepitch $N_{b}=2$ result in a significant reduction of conventional fault indices, which may lead to a misdiagnosis of such faults. Moreover, from the analysis presented in the previous section, one can safely conclude that, in cases when $N_{b}$ is equal to an even number, fault masking will take place. Here, the effects of an odd number of broken bars, each separated by a half pole-pitch, on rotor fault diagnostics are investigated. More precisely, three bars separated by a half pole-pitch $N_{b}=3$ are considered.

Shown in Fig. 16(a) are the experimental results evaluated using the MCSA diagnostic technique in the case when the squirrel-cage rotor has three bar breakages, each separated by one-half polepitch, $N_{b}=3$. For comparison purposes, Fig. 16(b) shows the experimental results in the case when the squirrel-cage rotor has only one broken bar. Considering Fig. 16(a) and (b), one should notice that, in both cases, the LSB components at $(1-2 s) f_{\text {syn }}$ are very close in value. More specifically, in the case of three broken bars, each separated by half pole-pitch, $\left|\mathrm{LSB}_{2 s f}\right|=-44.20 \mathrm{~dB}$, whereas in the case of one broken bar, $\left|\mathrm{LSB}_{2 s f}\right|=-44.27 \mathrm{~dB}$. Also, in the case of three broken bars, each separated by onehalf pole-pitch, one should notice a set of distinct sideband components at $(1 \pm 4 s) f_{\text {syn }}$, which hint at the possibility of the presence of additional nonadjacent faults. The same experimental results have been processed using MFPO diagnostic technique. The corresponding time-domain profiles of the pendulous oscillation are shown in Fig. 17. One should note that, in both cases, the values of the swing angles are in close agreement. This means that, in the case of three bar breakages $N_{b}=3$, separated by one-half pole-pitch, both diagnostic techniques yield fault indices corresponding to one broken bar. from the analysis previously presented, one should notice that, in the case of an odd number of nonadjacent bar breakages, each separated by one-half pole-pitch, conventional fault diagnostic indices, such as $\mathrm{LSB}_{2 s f}$ and/or swing angle $\Delta \delta_{1}$, yield values equivalent to one broken rotor bar. In other words, squirrel-cage rotors subjected to such faults can be easily misdiagnosed as having one bar breakage. from the previously presented results, one can safely conclude that, in the case of $N_{b}$ equal to an odd number $(3,5,7, \ldots)$, fault indices corresponding to one rotor-bar breakage will be produced.

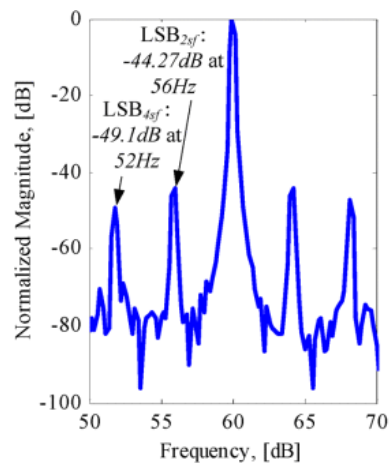

(a)

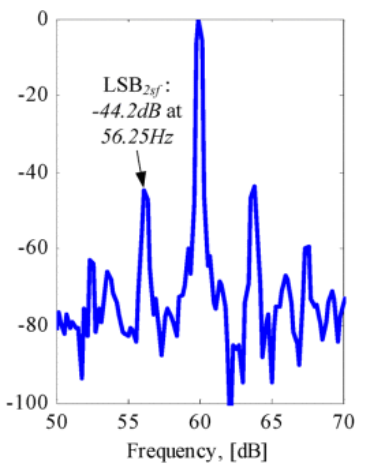

(b)

Fig. 16. Current frequency spectrum (MCSA): (a) Three broken bars separated by half pole-pitch, $90^{\circ}$ electrical. (b) One broken bar. Experimental tests (30 Nm, 1165 r/min). 


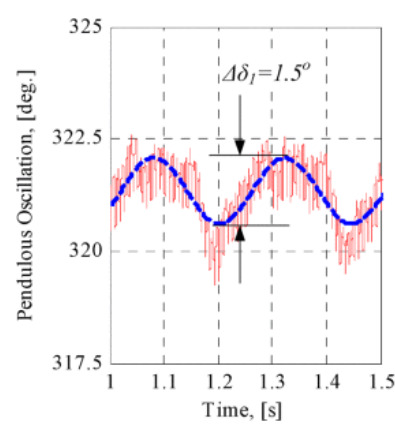

(a)

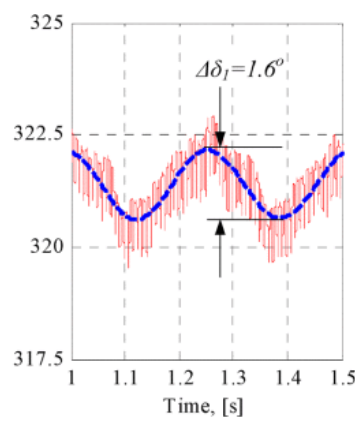

(b)

Fig. 17. Pendulous oscillation time-domain profile (MFPO): (a) Three broken bars separated by half pole-pitch, $90^{\circ}$ electrical. (b) One broken bar. Experimental tests (30 Nm, $1165 \mathrm{r} / \mathrm{min}$ ).

\section{B. Rotor-Bar Breakages Separated by One Pole-Pitch}

Here, experimental results for broken bars separated by one pole-pitch ( $180^{\circ}$ electrical) are presented. Again, the experimental results are evaluated using the two diagnostic techniques described in the previous sections. Similar to the previous section, two fault scenarios are considered, namely, two broken bars separated by one pole-pitch and $N_{b}$ broken bars separated by one pole-pitch.

1. Two Broken Bars Separated by One Pole-Pitch

Shown in Fig. 18(a) are the experimental results obtained for the case of two broken bars separated by one pole-pitch evaluated using the MCSA diagnostic technique. Also, for comparison purposes, results for two adjacent bar breakages are shown in Fig. 18(b). Comparing Fig. 18(a) and (b), one should notice that the magnitudes of the LSB components at $(1-2 s) f_{\text {syn }}$ are in close agreement. More specifically, in the case of two bars separated by one pole-pitch, $\left|\mathrm{LSB}_{2 s f}\right|=-38.00 \mathrm{~dB}$, which is in close agreement with the value obtained for the two adjacent bar fault $\left|\mathrm{LSB}_{2 s f}\right|=-40.05 \mathrm{~dB}$. Results obtained using the MCSA diagnostic technique have been verified using the MFPO approach. Shown in Fig. 19(a) and (b) are the pendulous oscillation time-domain profiles corresponding to the two fault scenarios. Again, one should notice a very close agreement between the swing angle values. This indicates that such nonadjacent faults yield fault indices $\left(\mathrm{LSB}_{2 s f}, \Delta \delta_{1}\right)$ corresponding to the adjacent faults with the same number of bar breakages.

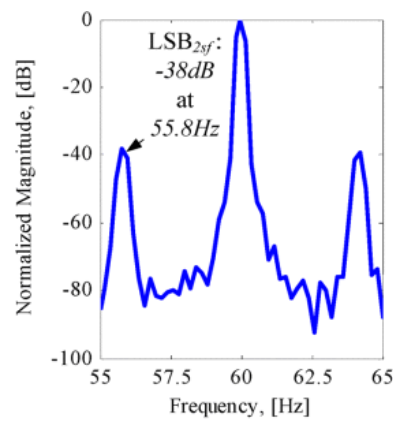

(a)

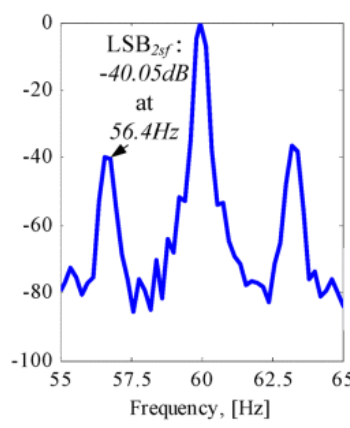

(b)

Fig. 18. Current frequency spectrum (MCSA): (a) Two broken bars separated by one pole-pitch, $180^{\circ}$ electrical. (b) Two adjacent broken bars. Experimental tests (30 Nm, 1165 r/min). 


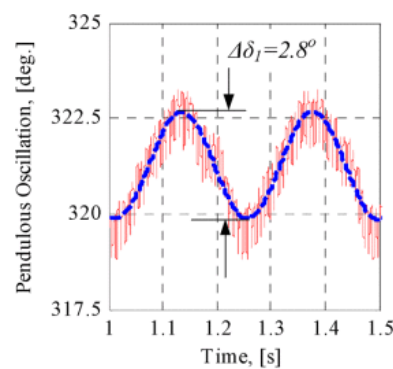

(a)

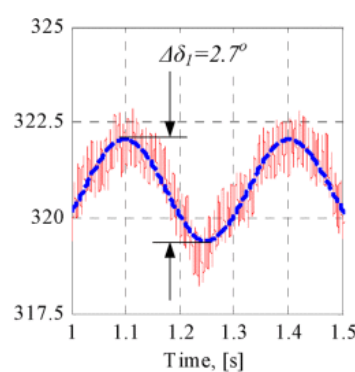

(b)

Fig. 19. Pendulous oscillation time-domain profile (MFPO): (a) Two broken bars separated by half pole-pitch, $180^{\circ}$ electrical. (b) Two adjacent broken bars. Experimental tests ( $30 \mathrm{Nm}, \sim 1165 \mathrm{r} / \mathrm{min}$ ).

2. $N_{b}$ Broken Bars Separated by One Pole-Pitch

In the previous section, it has been shown that, in the case of two nonadjacent rotor-bar breakage faults separated by one pole-pitch ( $180^{\circ}$ electrical), the fault indices ( $\left.\mathrm{LSB}_{2 s f}, \Delta \delta_{1}\right)$ corresponding to two adjacent bar breakages are produced. These results can be extended to show that, in cases when $N_{b}$ nonadjacent bar breakages are separated from another by one pole-pitch, fault indices corresponding to $N_{b}$ adjacent bar breakages will be produced. Hence, no difficulty should arise in diagnosing the presence of broken bars in the machine under these fault conditions. In summary, Table III delineates the different fault scenarios and fault indices that were studied in this paper. 
Table III Summary of Different Adjacent and Nonadjacent Fault Scenarios and Associated Fault Indices

\begin{tabular}{|c|c|c|c|c|c|}
\hline & & & MCSA & MFPO & LIKELIHOOD \\
\hline ADJACENT & & & $\begin{array}{l}\text { No Fault Masking } \\
\mathrm{LSB}_{2 s f} \text { and } \mathrm{USB}_{2 s f} \text { at }(1 \pm \\
2 s) f_{\text {syn }}\end{array}$ & $\begin{array}{l}\text { No Fault Masking } \\
\Delta \delta_{1} \text {, at } 2 s f_{\text {syn }}\end{array}$ & Most Frequent \\
\hline \multirow[t]{3}{*}{ NONADJACENT } & $\begin{array}{l}\text { Half Pole-Pitch } \\
\left(90^{\circ} \text { electrical) }\right.\end{array}$ & $N_{b}=$ even & $\begin{array}{l}\text { Fault Masked } \\
\text { Secondary fault effects result } \\
\text { in: } \mathrm{LSB}_{4 s f} \text { and } \mathrm{USB}_{4 s f} \text { at }(1 \pm \\
4 s) f_{\text {syn }}\end{array}$ & $\begin{array}{l}\text { Fault Masked } \\
\text { Secondary fault effects } \\
\text { result in: } \Delta \delta_{1} \text {, at } 4 s f_{\text {syn }}\end{array}$ & $\begin{array}{l}\text { Possible } \\
N_{b}=2 \text { (machines with } \\
\text { low number of rotor } \\
\text { bars per pole) }\end{array}$ \\
\hline & & $N_{b}=$ odd & $\begin{array}{l}\text { Fault Partially Masked } \mathrm{LSB}_{2 s f} \\
\text { and USB } \\
\text { one broken bar }\end{array}$ & $\begin{array}{l}\text { Fault Partially Masked } \\
\Delta \delta_{1} \text {, at } 2 s f_{\text {syn }} \\
\text { corresponding to one } \\
\text { broken bar }\end{array}$ & Unlikely \\
\hline & $\begin{array}{l}\text { One Pole-Pitch } \\
\left(180^{\circ}\right. \\
\text { electrical })\end{array}$ & $\begin{array}{l}N_{b} \\
=\text { even or odd }\end{array}$ & $\begin{array}{l}\text { No Fault Masking } \\
\mathrm{LSB}_{2 s f} \text { and } \mathrm{USB}_{2 s f} \text { at }(1 \pm \\
2 s) f_{\text {syn }}\end{array}$ & $\begin{array}{l}\text { No Fault Masking } \\
\Delta \delta_{1} \text {, at } 2 s f_{\text {syn }}\end{array}$ & Unlikely \\
\hline
\end{tabular}




\section{SECTION VI. Discussions and Conclusion}

In this paper, faults associated with squirrel-cage rotor structures of induction machines have been considered. More specifically, effects of adjacent and nonadjacent bar breakages on rotor fault diagnostics in squirrel-cage induction machines have been studied. It has been shown that nonadjacent bar breakages separated by one-half pole-pitch $\left(90^{\circ}\right.$ electrical) result in the masking of the commonly used fault indices, hence leading to a possible misdiagnosis of the machine. This masking problem has been addressed and partially solved in this paper. Namely, it has been shown that secondary saturation effects resulting from such nonadjacent bar breakages manifest themselves in sideband frequency components at $(1 \pm 4 s) f_{\text {syn }}$ in the frequency spectrum of motor currents and $4 s f_{\text {syn }}$ frequency components of the MFPO. Hence, these secondary saturation effects can be utilized for the diagnostics of such faults. Table III summarizes the different fault scenarios and corresponding fault indices that can be used for rotor fault diagnostics. The problem of a complete breakage of one or more bars could develop in machines which are monitored/inspected at regularly scheduled maintenance intervals. In this case, a failure can go through an incipient stage to a complete breakage of one or more bars in the period between scheduled inspections. Hence, the possibility of nonadjacent bar failure exists and could pose a potential problem. At present, no statistical data showing the frequency of occurrence of such nonadjacent rotor failures exists. However, one can identify some squirrel-cage designs that may be more prone to such nonadjacent failures. Squirrel-cage rotor structures with a low number of rotor bars per pole, such as the one studied in this paper, may be at higher risk of being misdiagnosed.

\section{References}

1. S. Nandi and H. A. Toliyat, "Fault diagnosis of electrical machinesA review", Proc. IEMD, pp. 219221, 1999-May.

2. M. Benbouzid and G. B. Kliman, "What stator current processing-based technique to use for induction motor rotor faults diagnosis?", IEEE Trans. Energy Convers., vol. 18, no. 2, pp. 238244, Jun. 2003.

3. "Report of large motor reliability survey of industrial and commercial installationsPart I", IEEE Trans. Ind. Appl., vol. IA-21, no. 4, pp. 853-864, Jul./Aug. 1985.

4. "Report of large motor reliability survey of industrial and commercial installationsPart II", IEEE Trans. Ind. Appl., vol. IA-21, no. 4, pp. 853-872, Jul./Aug. 1985.

5. P. F. Albrecht, J. C. Appiarius and D. K. Sharma, "Assessment of the reliability of motors in utility applicationsUpdated", IEEE Trans. Energy Convers., vol. EC-1, no. 1, pp. 39-46, Dec. 1986.

6. M. L. Sin, W. L. Soong and N. Ertugrul, "Induction machine on-line condition monitoring and fault diagnosisA survey", Proc. Australian Universities Power Eng. Conf., 2003.

7. A. H. Bonnett and G. C. Soukup, "Analysis of rotor failures in squirrel-cage induction motors", IEEE Trans. Ind. Appl., vol. 24, no. 6, pp. 1124-1130, Nov./Dec. 1988.

8. I. D. Lomax, "Assessment of induction motor cage fatigue life", Proc. 5th Int. Conf. Elect. Mach. Drives (Conf. Publ. 341), pp. 281-284, 1991-Sep.-1113.

9. J. F. Bangura and N. A. O. Demerdash, "Effects of broken bars/end-ring connectors and airgap eccentricities on ohmic and core losses of induction motors in ASD's using a coupled finite element-state space method", IEEE Trans. Energy Convers., vol. 15, no. 1, pp. 40-47, Mar. 2000. 
10. R. Carlson, "Inter-bar currents in the rotor of large three-phase cage induction motors: Analysis and detection", Proc. Symp. Diagnostics Elect. Mach. Power Electron. Drives, pp. 242-246, 2003Aug.

11. A. H. Bonnett and T. Albers, "Squirrel-cage rotor options for AC induction motors", IEEE Trans. Ind. Appl., vol. 37, no. 4, pp. 1197-1209, Jul./Aug. 2001.

12. J. S. Hsu, "Monitoring of defects in induction motors through air-gap torque observation", IEEE Trans. Ind. Appl., vol. 31, no. 5, pp. 1016-1021, Sep./Oct. 1995.

13. G. B. Kliman and R. A. Koegl, "Noninvasive detection of broken rotor bars in operating induction motors", IEEE Trans. Energy Convers., vol. 3, no. 4, pp. 873-879, Dec. 1988.

14. W. T. Thomson and I. D. Stewart, "Online current monitoring for fault diagnosis in inverter fed induction motors", Proc. IEE 3rd Int. Conf. Power Electron. Drives, pp. 432-435, 1988.

15. A. Bellini, F. Filippetti, G. Franceschini, C. Tassoni and G. B. Kliman, "Quantitative evaluation of induction motor broken bars by means of electrical signature analysis", IEEE Trans. Ind. Appl., vol. 37, no. 5, pp. 1248-1255, Sep./Oct. 2001.

16. W. T. Thomson and M. Fenger, "Current signature analysis to detect induction motor faults", IEEE Ind. Appl. Mag., vol. 7, no. 4, pp. 26-34, Jul./Aug. 2001.

17. S. H. Kia, H. Henao and G. A. Capolino, "A high-resolution frequency estimation method for three-phase induction machine fault detection", IEEE Trans. Ind. Electron., vol. 54, no. 4, pp. 2305-2314, Aug. 2007.

18. J.-H. Jung, J.-J. Lee and B.-H. Kwon, "Online diagnosis of induction motors using MCSA", IEEE Trans. Ind. Electron., vol. 53, no. 6, pp. 1842-1852, Dec. 2006.

19. B. Mirafzal and N. A. O. Demerdash, "On innovative methods of induction motor interturn and broken-bar fault diagnostics", IEEE Trans. Ind. Appl., vol. 42, no. 2, pp. 405-414, Mar./Apr. 2006.

20. B. Mirafzal and N. A. O. Demerdash, "Effects of load magnitude on diagnosing broken bar faults in induction motors using the pendulous oscillation of the rotor magnetic field orientation", IEEE Trans. Ind. Appl., vol. 41, no. 3, pp. 771-773, May/Jun. 2005.

21. B. Mirafzal and N. A. O. Demerdash, "Induction motor broken-bar fault diagnosis using the rotor magnetic field space-vector orientation", IEEE Trans. Ind. Appl., vol. 40, no. 2, pp. 534-542, Mar./Apr. 2004.

22. B. Mirafzal, Incipient fault diagnosis in squirrel-cage induction motors, Aug. 2005.

23. C. Kral, R. S. Wieser, F. Pirker and M. Schagginger, "Sequences of field-oriented control for the detection of faulty rotor bars in induction machinesThe Vienna monitoring method", IEEE Trans. Ind. Electron., vol. 47, no. 5, pp. 1042-1050, Oct. 2000.

24. V. Ostovic, Dynamics of Saturated Electric Machines, New York:Springer-Verlag, 1989.

25. V. Ostovic, "A method for evaluation of transient and steady state performance in saturated squirrel-cage induction machines", IEEE Trans. Energy Convers., vol. EC-1, no. 3, pp. 190-197, Sep. 1986.

26. V. Ostovic, "A simplified approach to magnetic equivalent-circuit modeling of induction machines", IEEE Trans. Ind. Appl., vol. 24, no. 2, pp. 308-316, Mar./Apr. 1988.

27. S. D. Sudhoff, B. T. Kuhn, K. A. Corzine and B. T. Branecky, "Magnetic equivalent circuit modeling of induction motors", IEEE Trans. Energy Convers., vol. 22, no. 2, pp. 259-270, Jun. 2007. 
28. H. Meshgin-Kelk, J. Milimonfared and H. A. Toliyat, "Interbar currents and axial fluxes in healthy and faulty induction motors", IEEE Trans. Ind. Appl., vol. 40, no. 1, pp. 128-134, Jan./Feb. 2004.

29. G. Y. Sizov, Analysis modeling and diagnostics of adjacent and nonadjacent broken rotor bars in squirrel-cage induction machines, Dec. 2007. 